\title{
Initiation of insulin glargine therapy in type 2 diabetes subjects suboptimally controlled on oral antidiabetic agents: results from the AT.LANTUS trial*
}

\author{
M. Davies, ${ }^{1, \dagger}$ F. Lavalle-González, ${ }^{2}$ F. Storms ${ }^{3}$ and R. Gomis ${ }^{4}$ \\ (on behalf of the AT.LANTUS Study Group ${ }^{\ddagger}$ )
}

${ }^{1}$ Department of Cardiovascular Sciences, University of Leicester, Leicester, UK

${ }^{2}$ Universidad Autonoma de Nuevo Leon, Monterrey NL, Mexico

${ }^{3}$ Mesos Diabetes Centrum, Utrecht, The Netherlands

${ }^{4}$ Hospital Clínic Universitari, Barcelona, Spain

Objective: For many patients with type 2 diabetes, oral antidiabetic agents (OADs) do not provide optimal glycaemic control, necessitating insulin therapy. Fear of hypoglycaemia is a major barrier to initiating insulin therapy. The AT.LANTUS study investigated optimal methods to initiate and maintain insulin glargine (LANTUS ${ }^{\circledR}$, glargine, Sanofi-aventis, Paris, France) therapy using two treatment algorithms. This subgroup analysis investigated the initiation of once-daily glargine therapy in patients suboptimally controlled on multiple OADs.

Research Design and Methods: This study was a 24-week, multinational (59 countries), multicenter (611), randomized study. Algorithm 1 was a clinic-driven titration and algorithm 2 was a patient-driven titration. Titration was based on target fasting blood glucose $\leq 100 \mathrm{mg} / \mathrm{dl}(\leq 5.5 \mathrm{mmol} / \mathrm{l})$. Algorithms were compared for incidence of severe hypoglycaemia [requiring assistance and blood glucose $<50 \mathrm{mg} / \mathrm{dl}(<2.8 \mathrm{mmol} / \mathrm{l})$ ] and baseline to end-point change in haemoglobin $\mathrm{A}_{1 \mathrm{c}}\left(\mathrm{HbA}_{1 \mathrm{c}}\right)$.

Results: Of the 4961 patients enrolled in the study, 865 were included in this subgroup analysis: 340 received glargine plus $1 \mathrm{OAD}$ and 525 received glargine plus $>1 \mathrm{OAD}$. Incidence of severe hypoglycaemia was $<1 \%$. $\mathrm{HbA}_{1 \mathrm{c}}$ decreased significantly between baseline and end-point for patients receiving glargine plus 1 OAD $(-1.4 \%$, p $<0.001$; algorithm $1-1.3 \%$ vs. algorithm $2-1.5 \% ; \mathrm{p}=0.03)$ and glargine plus $>1$ OAD $(-1.7 \%, \mathrm{p}<0.001$; algorithm $1-1.5 \%$ vs. algorithm $2-1.8 \%$; $\mathrm{p}=0.001$ ).

Conclusions: This study shows that initiation of once-daily glargine with OADs results in significant reduction of $\mathrm{HbA}_{1 \mathrm{c}}$ with a low risk of hypoglycaemia. The greater reduction in $\mathrm{HbA}_{1 \mathrm{c}}$ was seen in patients randomized to the patient-driven algorithm (algorithm 2) on 1 or $>1$ OAD.

Keywords: basal insulin analogues, insulin glargine, oral antidiabetic agents, titration, type 2 diabetes, treatment algorithms Received 20 August 2007; accepted 8 February 2008

\section{Correspondence:}

Prof. Melanie Davies, Department of Cardiovascular Sciences, University of Leicester, Leicester LE1 5WW, UK.

E-mail:

melanie.davies@uhl-tr.nhs.uk

*AT.LANTUS: A Trial comparing LANTUS Algorithms to achieve Normal blood glucose Targets in subjects with Uncontrolled blood Sugar. Data from the manuscript were presented as one oral [Davies M, et al. Diabetologia 47 (Suppl. 2): Abstract 146, 2004] and one poster [Lavalle-Gonzalez F, et al. ADA 2004; 12-LB], and published in abstract form [Davies M, et al. Diabetes 53 (Suppl. 2): A473 (Abstract 1980), 2004].

${ }^{\dagger}$ Duality of interest: M. D. has acted in a consultancy capacity and as a speaker for Novartis, Novo Nordisk, sanofi-aventis, Eli Lilly and Merck Sharpe Dohme. F. S. has served on advisory boards for sanofi-aventis.

${ }^{\ddagger}$ The full list of investigators is given in the Appendix. 
Achieving and maintaining tight glycaemic control for patients with type 2 diabetes is essential to delay progression of micro- and macrovascular complications [1]. Targets for haemoglobin $\mathrm{A}_{1 \mathrm{c}}\left(\mathrm{HbA}_{1 \mathrm{c}}\right)$ have been set as $<7.0,6.5-7.5$ and $<6.5 \%$ by the American Diabetes Association [2], National Institute for Health and Clinical Excellence in the UK [3] and the International Diabetes Federation [4], respectively. However, the majority of patients with type 2 diabetes are unable to reach target $\mathrm{HbA}_{1 \mathrm{c}}$ levels $[5,6]$.

Following diagnosis, patients are generally advised to make a number of lifestyle changes, focussed on increasing physical activity levels [7] and diet [8]. However, such programmes are usually insufficient by this stage of the diabetes [9]. The progressive nature of type 2 diabetes mellitus, characterized by a decline in $\beta$-cell function $[10,11]$ and deterioration in glycaemic control [12], means that pharmacologic interventions are usually required [13]. Oral antidiabetic agents (OADs), for example sulfonylureas, metformin and glitazones, are therapeutic interventions used in monotherapy or in combination. However, to achieve and maintain good glycaemic control, OADs, even in combination, are insufficient [14] and insulin therapy is often required [13].

Both patients and physicians may be reluctant to start insulin therapy $[6,15,16]$. The fear of hypoglycaemia, needle anxiety and weight gain are among the reasons cited that actively discourage insulin therapy. Therefore, it is important that for insulin therapy to be effective in patients with type 2 diabetes, these barriers must be overcome.

Insulin glargine (LANTUS ${ }^{\circledR}$, glargine) is the first clinically available basal analogue with no pronounced peak in activity and a 24-h duration of action following oncedaily administration [17]. In type 2 diabetes, insulin glargine has at least equivalent glycaemic control [18-20] with a lower incidence of hypoglycaemia compared with NPH insulin [20-25]. Therefore, insulin glargine could potentially be used as part of a more intensive treatment regimen to achieve target $\mathrm{HbA}_{1 \mathrm{c}}$ levels $\leq 7 \%$, with a lower risk of hypoglycaemia. Combination therapy of insulin glargine in conjunction with one or more OADs is an effective and simple regimen in patients with type 2 diabetes who have suboptimal control on OADs alone [26,27].

While little is known regarding the optimal titration regimen for initiating basal insulin therapy, the Treat-toTarget study [25] demonstrated that aggressive titration, in the context of an intensive and fully resourced clinical trial setting, can result in $\sim 60 \%$ of patients achieving target $\mathrm{HbA}_{1 \mathrm{c}}$ of $\leq 7 \%$.

We recently showed that two treatment algorithms, one largely clinic driven and the other primarily patient driven, can be introduced to a large cohort of subjects [28]. Given the large-scale nature of the AT.LANTUS study (59 countries, 4961 patients) and the diversity of prior treatment, it has been possible to perform a number of post hoc subanalyses on different subpopulations. One of the most likely clinical contexts in which basal insulin is initiated in type 2 diabetes is in those with suboptimal glycaemic control on OADs; thus, results in this particular subgroup are of particular relevance. Here, we report the findings of a subgroup analysis of insulin-naive patients suboptimally controlled with OADs who took part in the AT.LANTUS study.

\section{Research Design and Methods}

\section{Study Design}

This was a prospective, multinational (611 centres in 59 countries in Western and Eastern Europe, South America, Asia and Africa/Middle East), randomized controlled, parallel-design study of 24 weeks duration of 4961 type 2 diabetes patients. This study included only four mandatory clinical visits, similar to standard clinical practice. All patients gave informed consent in accordance with the Declaration of Helsinki, and the study was performed in accordance with Good Clinical Practice. Full details are available elsewhere [28].

Inclusion criteria for the total population [28] included subjects aged $\geq 18$ years on antidiabetic treatment (any oral and/or insulin therapy) for $>6$ months, $\mathrm{HbA}_{1 \mathrm{c}}$ levels $>7.0$ and $<12.0 \%$, body mass index values $<40 \mathrm{~kg} /$ $\mathrm{m}^{2}$ and a willingness to perform self-monitored blood glucose. Additional subgroup analysis criteria included insulin-naive patients suboptimally controlled with $>1$ OAD. Exclusion criteria were in accordance with the manufacturer's prescribing information.

In this paper, we discuss the subgroup analysis of subjects who were previously taking only OADs. At baseline, subjects were randomized ( $1: 1)$ to receive insulin glargine according to algorithm 1 (clinic-driven titration) or algorithm 2 (patient-driven titration) (table 1).

At baseline, the investigator decided whether to continue each OAD, in line with the prescribing information. Once it was decided whether the subject should take 1 or $>1 \mathrm{OAD}$, the dose of $\mathrm{OAD}(\mathrm{s})$ remained fixed and stable for the duration of the study. As thiazolidinediones were not licensed for use in combination with insulin at the time this study was conducted, for any patients using a thiazolidinedione during screening, the investigators were asked to switch therapy, in line with the prescribing information. 
Table 1 Summary of the two treatment titration regimens for insulin glargine

\begin{tabular}{|c|c|c|}
\hline \multirow[b]{2}{*}{$\begin{array}{l}\text { Mean FBG for the previous } \\
3 \text { consecutive days }\end{array}$} & \multicolumn{2}{|c|}{ Increase in daily basal insulin glargine dose $(U)^{*}$} \\
\hline & $\begin{array}{l}\text { Algorithm 1†: titration at every visit; } \\
\text { physician-driven }\end{array}$ & $\begin{array}{l}\text { Algorithm } 2 \dagger \text { : titration every } 3 \text { days; } \\
\text { subject-driven and reviewed by } \\
\text { physicians at each visit }\end{array}$ \\
\hline Starting dose & $10 \mathrm{U} /$ day & $\begin{array}{l}\text { Numerically equivalent to } F B G \text { in preceding } 7 \text { days } \\
\text { (e.g. FBG }=12 \mathrm{mmol} / \mathrm{l} \text {, insulin dose }=12 \mathrm{U} / \text { day) }\end{array}$ \\
\hline$\geq 100$ and $<120 \mathrm{mg} / \mathrm{dl}(\geq 5.6$ and $<6.7 \mathrm{mmol} / \mathrm{l})$ & $0-2$ (at the discretion of the investigator) $\neq$ & $0-2$ (at the discretion of the investigator) $\neq$ \\
\hline$\geq 120$ and $<140 \mathrm{mg} / \mathrm{dl}(\geq 6.7$ and $<7.8 \mathrm{mmol} / \mathrm{l})$ & 2 & 2 \\
\hline$\geq 140$ and $<180 \mathrm{mg} / \mathrm{dl}(\geq 7.8$ and $<10 \mathrm{mmol} / \mathrm{l})$ & 4 & 2 \\
\hline$\geq 180 \mathrm{mg} / \mathrm{dl}(\geq 10 \mathrm{mmol} / \mathrm{l})$ & $6-8$ (at the discretion of the investigator) $\neq$ & 2 \\
\hline
\end{tabular}

FBG $=$ fasting blood glucose.

*Target FBG $\leq 100 \mathrm{mg} / \mathrm{dl}(\leq 5.5 \mathrm{mmol} / \mathrm{l})$.

†Reviewed by physician at each visit, either in person or over the telephone; titration occurred only in the absence of blood glucose levels $<72 \mathrm{mg} / \mathrm{dl}(<4.0 \mathrm{mmol} / \mathrm{l})$.

$\ddagger$ Magnitude of daily basal dose was at the discretion of the investigator.

\section{Objectives}

The primary objective of the full study was to compare the two treatment algorithms for the initiation and maintenance of insulin glargine based on the incidence of severe hypoglycaemia, defined according to criteria used in the Diabetes Control and Complications Trial (DCCT) [29,30].

The primary outcome measure for this subgroup analysis was the comparison between algorithms for the incidence of severe, symptomatic and nocturnal hypoglycaemia. Secondary outcomes included glycaemic control $\left[\mathrm{HbA}_{1 \mathrm{c}}\right.$ and fasting blood glucose (FBG)] and change in insulin dose from baseline. The study end-point was defined by the subject's last observation (visit 12 for those completing the study, or last clinic for those missing data on visit 12). If a subject discontinued treatment permanently before the planned study ends, the last evaluation before discontinuation was considered for the end-point analysis.

\section{Measurements and Safety}

At screening, biochemistry and haematology measurements were taken. $\mathrm{HbA}_{1 \mathrm{c}}$ and weight were measured at screening, baseline and weeks 12 and 24. Analyses of $\mathrm{HbA}_{1 \mathrm{c}}$ were performed by the laboratory of each participating site, either according to the DCCT standard method or according to a DCCT-aligned method within a documented quality controlled system. FBG levels on 6 consecutive days before and on the day of a visit were measured by subjects weekly from baseline to week 24 . Glucose monitors were provided for self-monitored blood glucose. The glucose meters used a standardized platform for the entire study and reported results in whole blood. Data and calibration of blood glucose meters were verified at clinical visits.
Safety assessments in each treatment algorithm included adverse event (AE) reporting, excluding the primary and secondary outcomes. All AEs, including nontreatment-emergent AEs, were recorded.

\section{Statistical Methods}

The statistical and reporting methods used in this subanalysis were similar to those used in the main AT. LANTUS study [28]. In the full study population, the primary efficacy variable (frequency of severe hypoglycaemia) was evaluated using a two-sided $90 \%$ confidence interval (CI), with equivalence declared if the $90 \%$ CI was contained in the pre-defined equivalence boundaries $(-1.5,1.5 \%)$. For analyses presented here, patients treated at baseline with $>1 \mathrm{OAD}$ were isolated and a descriptive analysis was produced. Analyses were performed for two subgroups defined according to the number of OADs received at randomization ( 1 or $>1$ $\mathrm{OAD}$ ) and who remained on the same treatment regimen throughout the study. All analyses presented here were performed on an exploratory basis. The analyses were undertaken on non-randomized subgroups of patients without adjustment for multiple testing and were based on the per-protocol population. Changes from baseline in $\mathrm{HbA}_{1 \mathrm{c}}$, FBG, body weight and insulin dose were analysed using analysis of covariance. Student's $t$-test and the chi-squared test were also used as appropriate. A $\mathrm{p}$ value of $<0.05$ was considered statistically significant. Statistical analyses were performed using SAS version 8 (SAS, Cary, NC, USA).

\section{Results}

Results of independent audits performed in accordance with Good Clinical Practice concluded that the trial data 
were reliable, verifiable and retrievable. The results from the full study population $(n=4961)$ can be found elsewhere [28]. A total of 865 subjects with type 2 diabetes, previously suboptimally controlled on multiple OADs, were included in this subgroup analysis; of these patients, 340 received insulin glargine plus 1 OAD and 525 received insulin glargine plus $>1$ OAD (intentionto-treat population of this subgroup). Of patients receiving 1 OAD, 316 (algorithm 1: 170 and algorithm 2: 146) completed the study to form the per-protocol population; reasons for discontinuation, algorithm 1 vs. algorithm 2, were patient not followed to final visit (four vs. eight subjects) and major protocol violations (six vs. six subjects). In patients receiving $>1$ OAD, 499 (algorithm 1: 256 and algorithm 2: 243) completed the study to form the per-protocol population; reasons for discontinuation, algorithm 1 vs. algorithm 2, were patient not followed to final visit (five vs. seven subjects) and major protocol violations (eight vs. six subjects).

Subject demographics and baseline characteristics were broadly similar between the two treatment groups and within each algorithm, although patients in the $>1$ OAD treatment group tended to have a longer duration of OAD treatment compared with those in the 1 OAD treatment group (table 2).
While data presented are based on the per-protocol analysis, full intention-to-treat analyses were performed. The results were virtually identical and, therefore, did not differ clinically or statistically and are not presented here.

\section{Hypoglycaemia}

The incidence of severe, symptomatic and nocturnal hypoglycaemia in patients receiving insulin glargine via either treatment algorithm plus either $1 \mathrm{OAD}$ or $>1 \mathrm{OAD}$ is summarized in table 3 . The incidence of severe hypoglycaemia was $<1 \%$ in both treatment groups, with no significant difference between the treatment algorithms.

\section{Haemoglobin $A_{1 c}$}

In subjects receiving insulin glargine plus $1 \mathrm{OAD}$, there was a significant baseline to end-point decrease in $\mathrm{HbA}_{1 \mathrm{c}}$ in both algorithms (figure 1A). Algorithm 2 was associated with a greater reduction compared with algorithm 1 ( -1.5 vs. $-1.3 \%, p=0.03)$. Significant reductions in $\mathrm{HbA}_{1 \mathrm{c}}$ from baseline to end-point were also observed in patients receiving insulin glargine plus $>1$ OAD in both algorithms (figure 1A). Algorithm 2 was associated with

Table 2 Baseline demographics and characteristics of the subgroup analysis subjects treated with insulin glargine by algorithm 1 and algorithm 2 (per-protocol population)

\begin{tabular}{|c|c|c|c|c|}
\hline \multirow[b]{2}{*}{ Demographics and characteristics } & \multicolumn{2}{|c|}{ Insulin glargine + 1 OAD $(n=316)$} & \multicolumn{2}{|c|}{ Insulin glargine $+>1$ OAD $(n=499)$} \\
\hline & Algorithm 1 (n = 170) & Algorithm 2 (n = 146) & Algorithm 1 (n = 256) & Algorithm 2 (n = 243) \\
\hline Age (years) & $57.9 \pm 10.2$ & $56.6 \pm 11.0$ & $57.2 \pm 10.3$ & $57.3 \pm 10.5$ \\
\hline Body mass index $\left(\mathrm{kg} / \mathrm{m}^{2}\right)$ & $29.3 \pm 4.6$ & $29.2 \pm 4.6$ & $29.3 \pm 4.6$ & $28.9 \pm 4.3$ \\
\hline \multicolumn{5}{|l|}{ Sex } \\
\hline Male (\%) & 51.2 & 58.9 & 50.8 & 52.7 \\
\hline Female (\%) & 48.8 & 41.1 & 49.2 & 47.3 \\
\hline Age at onset of diabetes (years) & $48.6 \pm 9.5$ & $46.8 \pm 10.7$ & $46.8 \pm 10.1$ & $46.7 \pm 10.3$ \\
\hline Diabetes duration (years) & $9.3 \pm 5.5$ & $9.7 \pm 6.5$ & $10.4 \pm 5.7$ & $10.5 \pm 6.6$ \\
\hline Duration of OAD therapy (years) & $7.9 \pm 5.7$ & $7.7 \pm 5.8$ & $9.2 \pm 5.1$ & $9.4 \pm 6.2$ \\
\hline $\mathrm{HbA}_{1 \mathrm{c}}(\%)$ & $9.1 \pm 1.3$ & $9.1 \pm 1.3$ & $9.1 \pm 1.3$ & $9.2 \pm 1.2$ \\
\hline Fasting blood glucose, mg/dl (mmol/l) & $180.7 \pm 45.8(10.0 \pm 2.5)$ & $186.2 \pm 55.3(10.3 \pm 3.1)$ & $180.4 \pm 46.5(10.0 \pm 2.6)$ & $183.7 \pm 47.8(10.2 \pm 2.7)$ \\
\hline
\end{tabular}

$\mathrm{HbA}_{1 \mathrm{c}}$, haemoglobin $\mathrm{A}_{1 \mathrm{c}}$; OAD, oral antidiabetic agent.

Data are mean \pm s.d. unless otherwise stated.

Table 3 Incidence of severe, symptomatic and nocturnal hypoglycaemia

\begin{tabular}{|c|c|c|c|c|c|c|}
\hline & \multicolumn{3}{|c|}{ Insulin glargine + 1 OAD $(n=316)$} & \multicolumn{3}{|c|}{ Insulin glargine $+>1$ OAD $(n=499)$} \\
\hline & $\begin{array}{l}\text { Algorithm } 1 \\
(\mathrm{n}=170)\end{array}$ & $\begin{array}{l}\text { Algorithm } 2 \\
(n=146)\end{array}$ & $\mathbf{p}$ & $\begin{array}{l}\text { Algorithm } 1 \\
(\mathrm{n}=256)\end{array}$ & $\begin{array}{l}\text { Algorithm } 2 \\
(n=243)\end{array}$ & $\mathbf{p}$ \\
\hline Severe hypoglycaemia $(\%<2.8 \mathrm{mmol} / \mathrm{l})$ & 0 & 0 & $\mathrm{~N} / \mathrm{S}$ & $<1$ & $<1$ & $\mathrm{~N} / \mathrm{S}$ \\
\hline Symptomatic hypoglycaemia (\%) & 13.5 & 15.1 & $\mathrm{~N} / \mathrm{S}$ & 18.8 & 16 & $\mathrm{~N} / \mathrm{S}$ \\
\hline Nocturnal hypoglycaemia (\%) & $<1$ & 2.1 & $\mathrm{~N} / \mathrm{S}$ & 2.7 & 4.5 & $\mathrm{~N} / \mathrm{S}$ \\
\hline
\end{tabular}

OAD, oral antidiabetic agent; N/S, non-significant. 

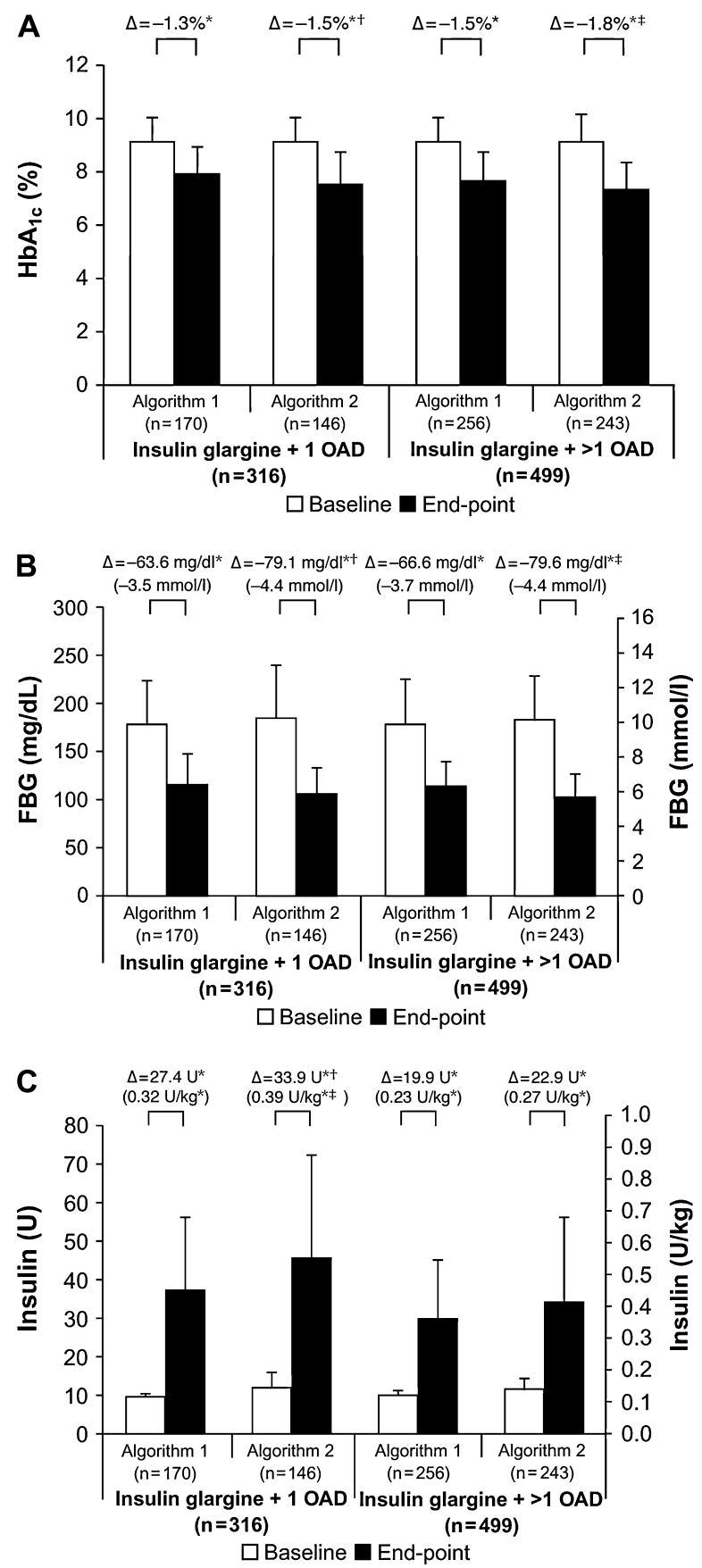

a greater reduction compared with algorithm 1 (-1.8 vs. $-1.5 \%, \mathrm{p}=0.001)$.

At end-point, in subjects receiving insulin glargine plus $1 \mathrm{OAD}, 24 \%$ had reached target $\mathrm{HbA}_{1 \mathrm{c}}$ levels $\leq 7 \%$ with algorithm 1 compared with $38 \%$ of subjects with algorithm 2 ( $p=0.009)$, and in subjects receiving insulin glargine plus $>1 \mathrm{OAD}, 31 \%$ had reached target $\mathrm{HbA}_{1 \mathrm{c}}$ levels $\leq 7 \%$ with algorithm 1 compared with $43 \%$ of subjects with algorithm $2(p=0.007)$. Significantly more
Fig. 1 (A) $\mathrm{HbA}_{1 \mathrm{c}}$ levels at baseline (open bars) and endpoint (closed bars) in the per-protocol population receiving insulin glargine via algorithm 1 or algorithm 2 plus either $1 \mathrm{OAD}$ or $>1$ OAD. ${ }^{*} \mathrm{p}<0.001$ for baseline to end-point change. $\dagger p=0.03$ and $\ddagger \mathrm{p}=0.001$ for difference between algorithms for baseline to end-point change. The magnitude of change in $\mathrm{HbA}_{1 \mathrm{c}}$ from baseline to end-point for algorithm 1 vs. Algorithm 2 in the intent-to-treat population was 1.9 and $1.6 \%$, respectively. (B) FBG levels at baseline (open bars) and end-point (closed bars) in the perprotocol population receiving insulin glargine via algorithm 1 or algorithm 2 plus either 1 OAD or $>1$ OAD. ${ }^{*} \mathrm{p}<0.001$ for baseline to end-point change. $\dagger \mathrm{p}=0.001$ and $\ddagger \mathrm{p}<0.001$ for difference between algorithms for baseline to end-point change. (C) Insulin dose at baseline (open bars) and end-point (closed bars) in the per-protocol population receiving insulin glargine via algorithm 1 or algorithm 2 plus either $1 \mathrm{OAD}$ or $>1 \mathrm{OAD} .{ }^{*} \mathrm{p}<0.001$ for baseline to end-point change. $\dagger p=0.04$ and $\ddagger p=0.03$ for difference between treatment algorithms in baseline to end-point change in daily total insulin dose $(\dagger)$ and daily total weightadjusted insulin dose $(\ddagger) . \mathrm{HbA}_{1 \mathrm{c}}$, haemoglobin $\mathrm{A}_{1 \mathrm{c}}$; FBG, fasting blood glucose; OAD, oral antidiabetic agent.

subjects achieved $\mathrm{HbA}_{1 \mathrm{c}}$ levels $\leq 7 \%$ without experiencing either severe or nocturnal hypoglycaemia in algorithm 2 vs. algorithm 1 in subjects receiving both insulin glargine plus 1 OAD (33 vs. $21 \%, p=0.02$ ) and insulin glargine plus $>1$ OAD (37 vs. $28 \%, p=0.03$ ).

\section{Fasting Blood Glucose}

FBG decreased significantly from baseline to end-point in all subgroups ( $\mathrm{p}<0.001$; figure $1 \mathrm{~B}$ ), but the reduction in FBG was significantly greater for subjects randomized to algorithm 2 compared with algorithm 1 for subjects receiving insulin glargine plus 1 OAD $[-79.1 \pm 55.3$ $(4.4 \pm 3.1 \mathrm{mmol} / \mathrm{l})$ vs. $63.6 \pm 51.7 \mathrm{mg} / \mathrm{dl} \quad(3.5 \pm 2.9$ $\mathrm{mmol} / \mathrm{l}), \mathrm{p}=0.001$ ] and subjects receiving insulin glargine plus $>1$ OAD $[79.6 \pm 48.3(4.4 \pm 2.7 \mathrm{mmol} / \mathrm{l})$ vs. $-66.6 \pm 51.6(3.7 \pm 2.9 \mathrm{mmol} / \mathrm{l}), \mathrm{p}<0.001]$.

\section{Insulin Glargine Dose}

For patients receiving $1 \mathrm{OAD}$, the increases in insulin dose were significantly greater for patients randomized to algorithm 2 [+33.9 U, range: -8 to $+128 \mathrm{U}(+0.39 \mathrm{U} / \mathrm{kg})]$ compared with algorithm 1 ( $+27.4 \mathrm{U}, \mathrm{p}=0.04$; range: -2 to $+104 \mathrm{U}(+0.32 \mathrm{U} / \mathrm{kg}, \mathrm{p}=0.03)$; figure $1 \mathrm{C}]$. For patients receiving $>1 \mathrm{OAD}$, the increases in insulin dose were not significantly different in the patients randomized to algorithm 1 [+19.9 U; range: -6 to $+100 \mathrm{U}(+0.23 \mathrm{U} / \mathrm{kg})]$ or algorithm $2[+22.8 \mathrm{U}, \mathrm{p}=0.57$; range: -16 to $+114 \mathrm{U}$ $(+0.27 \mathrm{U} / \mathrm{kg}, \mathrm{p}=0.20)$; figure $1 \mathrm{C}]$. 


\section{Body Weight}

In subjects receiving both $1 \mathrm{OAD}$ and $>1 \mathrm{OAD}$, there was a modest statistically significant $(p<0.001)$ increase in body weight from baseline to end-point with both algorithm 1 [81.2 \pm 15.5 to $82.8 \pm 15.9$ (mean change $+1.6 \pm$ $3.3) \mathrm{kg}$ and $81.3 \pm 16.5$ to $83.2 \pm 16.8(+1.9 \pm 3.5) \mathrm{kg}$, respectively] and algorithm $2[82.1 \pm 15.3$ to $83.5 \pm 15.5$ $(+1.4 \pm 3.4) \mathrm{kg}$ and $78.5 \pm 15.7$ to $80.6 \pm 16.2(+2.1 \pm$ $3.3) \mathrm{kg}$, respectively]. There was no significant difference in weight change between algorithms.

\section{Safety}

In the main study, treatment-emergent AEs were reported in $48.7 \%$ of patients; their overall frequency was similar between the algorithms [28]. In this subgroup analysis, the incidence of AEs was similar to that in the main study (data not shown).

\section{Conclusions}

The AT.LANTUS study is one of the largest randomized clinical studies ( $\mathrm{n}=4961$ patients) of glycaemic management performed in subjects with type 2 diabetes, and the results will be applicable to many patients in a clinical setting [28]. This subgroup analysis, undertaken in 865 subjects, included all insulin-naive patients who were previously suboptimally controlled on multiple OADs. The results presented here demonstrate that two simple insulin initiation and treatment algorithms were highly effective in safely achieving and maintaining glycaemic control. Furthermore, these results were achieved regardless of concomitant OAD therapy $(+1 \mathrm{OAD}$ or $>1$ OAD) along with a very low incidence of severe hypoglycaemia.

We have previously published results from the overall population; changes in $\mathrm{HbA}_{1 \mathrm{c}}$ were -1.08 and $-1.22 \%$ for algorithms 1 and 2, respectively [28]. Meanwhile, in this subgroup analysis, patient-driven titration of insulin dose achieved the greater improvement in $\mathrm{HbA}_{1 \mathrm{c}}(+1 \mathrm{OAD}-1.5 \%,>1 \mathrm{OAD}-1.8 \%)$ compared with physician-driven titration (+1 OAD: $-1.3 \% ;>1$ OAD: $-1.5 \%)$. We also show that patient-driven titration of basal insulin with multiple OAD therapy is associated with the greatest improvement in $\mathrm{HbA}_{1 \mathrm{c}}$ without an increased risk of symptomatic hypoglycaemia. In separate subgroup analyses, initiation of insulin glargine achieved reductions of $0.8-0.9 \%$ in $\mathrm{HbA}_{1 \mathrm{c}}$ for patients previously on NPH insulin [31] and $1.5 \%$ for patients previously on twice-daily premixed insulin plus OADs [32].
The fears of weight gain and hypoglycaemia are significant barriers to the initiation of insulin therapy in type 2 diabetes [15,33]. In this subgroup analysis, weight gain was relatively modest (range 1.4-2.1 kg over 24 weeks) in the context of significant improvement in glycaemic control, with $24-43 \%$ of patients reaching target $\mathrm{HbA}_{1 \mathrm{c}}$ levels of $\leq 7.0 \%$. This occurred with a comparatively low incidence of severe hypoglycaemia. Furthermore, these benefits were seen regardless of concomitant OAD therapy. Therefore, therapy with basal insulin glargine plus OADs may provide the impetus to overcome the fears of hypoglycaemia and weight gain.

In our study, no patients in the insulin glargine $+1 \mathrm{OAD}$ group experienced severe hypoglycaemia and $<1 \%$ of the patients in the $>1$ OAD group experienced severe hypoglycaemia, which compares favourably with that reported by the UK Prospective Diabetes Study (UKPDS; $2.3 \%$ for patients treated with insulin) [34]. Furthermore, our study was of the patients with long-standing type 2 diabetes, with a mean duration since diagnosis of 10 years and mean duration of OAD therapy of $>7$ years, whereas the UKPDS included only newly diagnosed (insulin and OAD naive) patients.

In the Treat-To-Target trial [25], which used a forced titration schedule with doses monitored by clinical staff, $36.2 \%$ of patients achieved a target $\mathrm{HbA}_{1 \mathrm{c}}$ of $\leq 7.0 \%$ without an episode of documented nocturnal hypoglycaemia. In our study, a similar proportion of patients achieved the target $\mathrm{HbA}_{1 \mathrm{c}}$ of $\leq 7.0 \%$ without experiencing nocturnal hypoglycaemia. The proportion of patients who achieved target $\mathrm{HbA}_{1 \mathrm{c}}$ without experiencing hypoglycaemia was statistically superior in the patient-driven titration group, regardless of concomitant OAD therapy (28.3 and $37.3 \%$ for patients in algorithms 1 and 2, respectively; intent-to-treat population). This occurred in conjunction with larger reductions in $\mathrm{HbA}_{1 \mathrm{c}}$ (1.9 vs. $1.6 \%$; intent-to-treat population). Furthermore, the patients in our study had a lower rate of hypoglycaemia without including unlicensed thiazolidinedione use. In our study, the exclusion of thiazolidinediones may have limited the proportion of patients who achieved target $\mathrm{HbA}_{1 \mathrm{c}}(\leq 7 \%)$. In the past, and increasingly now, thiazolidinediones in combination with insulin have demonstrated good reductions in $\mathrm{HbA}_{1 \mathrm{c}}$ in type 2 diabetes $[25,35,36]$. A further reason for the lower proportion of patients reaching $\mathrm{HbA}_{1 \mathrm{c}}<7 \%$ is that we did not force the titration of insulin glargine, whereas the Treat-toTarget study did. As a result, the rates of hypoglycaemia were lower in our study. This suggests that titration of insulin glargine dose could be more aggressive, to better reach treatment targets, although this must be balanced against the inevitable risk of hypoglycaemia. 
While a shortcoming of the current study may be the lack of a placebo arm, the reduction in $\mathrm{HbA}_{1 \mathrm{c}}(>1 \%)$ observed in this study is greater than that might be expected as a result of a placebo effect.

The patients included in this analysis had relatively long-standing type 2 diabetes ( $>9$ years) and $\mathrm{HbA}_{1 \mathrm{c}}$ $>9 \%$ on average. It is evident that a change in therapy was warranted. The addition of once-daily basal insulin to their oral antidiabetic regimen led to clinically important improvements in glycaemic control (including $\mathrm{HbA}_{1 \mathrm{c}}$ and FBG) with low risk of hypoglycaemia. Nevertheless, a number of patients had $\mathrm{HbA}_{1 \mathrm{c}}$ levels above the recommended levels (i.e. $\leq 7 \%$ ). One option would be to use a more aggressive titration regimen, which may have increased the proportion of subjects achieving target $\mathrm{HbA}_{1 \mathrm{c}} \leq 7 \%$, as in the LANMET study [21], which is discussed below. Alternatively, the addition of one or several doses of a rapid-acting insulin at mealtime to the therapeutic regimen may be warranted for those patients who were not reaching target $\mathrm{HbA}_{1 \mathrm{c}}$ levels once the basal insulin dose is fully optimized. Indeed, such an approach was also suggested in the American Diabetes Association/European Association for the Study of Diabetes consensus statement [37]. Nevertheless, this concept will need objective testing.

A further shortcoming of the present study is that it was conducted as an exploratory analysis of a large subgroup $(\mathrm{n}=865)$ of patients from the original AT.LANTUS study ( $\mathrm{n}=4961$ patients). As such, the analyses were mainly descriptive. However, as a large proportion of patients from the original study were included in the analyses presented here and that the analysis includes a similar number of patients used in trials such as the Treat-to-Target study [25], one would expect that the results show a high degree of statistical power and support the need for confirmatory studies.

While additional prospective randomized studies may be necessary to further confirm the results reported, it is evident that the current subanalysis confirms the results of the Treat-to-Target study. The distinguishing feature here is that patient-driven titration appears to achieve greater $\mathrm{HbA}_{1 \mathrm{c}}$ benefits, with more patients reaching target $\mathrm{HbA}_{1 \mathrm{c}}$ at end-point, twice the percentage of patients reaching target FBG (72 vs. $36 \%$ ) and a lower incidence of severe hypoglycaemia, all in the absence of the use of thiazolidinediones.

Physicians currently face a number of options for transferring patients from combination OAD therapy to insulin, including multiple daily or basal injections and whether to continue or change OAD therapy. In a recent meta-analysis [38] of four trials comparing insulin glargine with NPH insulin in patients with type 2 diabetes
$[22,24,25,39]$, insulin glargine was associated with significantly lower incidence of hypoglycaemia in conjunction with improved $\mathrm{HbA}_{1 \mathrm{c}}$, and this occurred despite similar increases in dose from baseline to end-point (20-28 weeks) from 21 to $38 \mathrm{U}$ for insulin glargine and 21 to $37 \mathrm{U}$ for NPH insulin. The relative merits of twicedaily premixed insulin vs. once-daily basal insulin are often debated. One study has shown that once-daily insulin glargine plus metformin was more effective at lowering $\mathrm{HbA}_{1 \mathrm{c}}$ than a twice-daily premixed insulin regimen, but a criticism was that metformin was discontinued in the premixed insulin arm, and a conventional premixed insulin was used [40]. In comparison, in two studies, where OADs were continued and comparing biphasic analogue mixtures (Lispro Mix 75/25 or Aspart Mix 70/30) with insulin glargine, the premixed insulin regimens were associated with greater reductions in $\mathrm{HbA}_{1 \mathrm{c}}[35,41]$. However, the premixed insulin regimens were also associated with significantly higher incidence of hypoglycaemia and greater weight gain compared with insulin glargine.

In the LANMET study [21], which investigated the addition of either insulin glargine or NPH insulin to metformin therapy, the percentages of patients in the insulin glargine group experiencing hypoglycaemia were 46 and $43 \%$ during weeks 0-12 and 13-24, respectively. By comparison, a smaller proportion of patients experienced symptomatic hypoglycaemia in our study $(<19 \%)$. This may be because of the titration methods used in the two studies, insulin doses reached $\sim 60 \mathrm{U}$ by week 24 in the LANMET study, whereas in our study, the mean insulin dose was $<46 \mathrm{U}$ for all subanalysis groups. This balance between high insulin dose, change in $\mathrm{HbA}_{1 \mathrm{c}}$ and risk of hypoglycaemia is a trade-off that will need to be acceptable for the patient. In our study, we used algorithm based on avoidance of hypoglycaemia, with allowances for decreasing insulin dose in the event of regular hypoglycaemia, thus limiting the extent to which insulin doses can be increased.

In a study investigating continued sulphonylurea and metformin with either insulin glargine or rosiglitazone (patients previously treated with sulfonylurea and metformin), insulin glargine was associated with significantly improved glycaemic control $\left(\mathrm{HbA}_{1 \mathrm{c}}\right.$ and $\left.\mathrm{FBG}\right)$ [27]. While the incidence of hypoglycaemia was higher in the insulin glargine group, less weight gain and fewer AEs occurred in the insulin glargine group.

In studies with insulin glargine [25,27,40,41], the starting dose of insulin glargine was typically 10-20 U. By end-point (20-28 weeks), the dose had increased to 25-40 U. In our study, patients in both treatment algorithms with $>1$ OAD achieved similar doses at week 
24. However, those patients on 1 OAD achieved a greater increase in basal insulin dose when encouraged to self-titrate.

Effective and efficient use of scarce healthcare resources is an important aspect of care. An approach that increases patient-driven management is as effective and reduces the need for face-to-face contact with healthcare professionals is thus potentially a more effective use of healthcare resources. However, it has been reported that healthcare providers underestimate the proportion of patients who would be willing to take part in decision making about their treatment [42].

The approach to insulin initiation and dose titration with a single injection of insulin titrated against an FBG level [37], as used here, is a simple and consistent approach, which is conducive to being taught in a group setting, and has also been shown to be a more effective use of healthcare professional time. Indeed, in a study by Yki-Jarvinen et al., where patients were encouraged to self-adjust their insulin dose, with education delivered in either a group or an individual setting, improvements in $\mathrm{HbA}_{1 \mathrm{c}}$ were similar in both arms (group: 8.8$6.8 \%$, individual: $8.7-6.9 \%$ ). However, the time spent by the healthcare professional per patient was significantly less with group than with Individual education (2.2 vs. $4.2 \mathrm{~h}, \mathrm{p}<0.001$ ) [43].

The findings presented here support those observed in the full cohort that two simple, widely applicable titration algorithms (either patient- or physician-driven) for the initiation of glargine can be implemented in clinical practice with low incidence of hypoglycaemia. We also show that patient-driven dose titration achieves more pronounced improvements in glycaemic control compared with physician-driven titration, and this improvement is not associated with an increased risk of hypoglycaemic episodes. Moreover, subjects with type 2 diabetes, suboptimally controlled with OADs, can safely and effectively participate in the management of their treatment if given simple information and support, with the potential to significantly reduce the burden of care on healthcare professionals. Further intensification of the insulin regimen would be expected to help more patients reach their recommended treatment targets.

\section{Acknowledgements}

This study was sponsored by sanofi-aventis. Editorial support for this article was provided through the global publications group of sanofi-aventis. We would like to thank all of the investigators and patients participating in AT.LANTUS. M. D. has also received grants in support of investigator-led and internal trials from Servier, Novartis,
Novo Nordisk, Pfizer and sanofi-aventis. R. G. has received financial support from sanofi-aventis.

\section{References}

1 Davidson JA. Treatment of the patient with diabetes: importance of maintaining target $\mathrm{HbA}(1 \mathrm{c})$ levels. Curr Med Res Opin 2004; 20: 1919-1927.

2 American Diabetes Association. Standards of medical care in diabetes - 2006. Diabetes Care 2006; 29: S4-S42.

3 Department of Health. National Service Framework for Diabetes: Standards. London: Department of Health, 2002.

4 IDF Clinical Guidelines Task Force. Global Guideline for Type 2 Diabetes. Brussels: International Diabetes Federation, 2005.

5 Eliasson B, Cederholm J, Nilsson P, Gudbjornsdottir S. The gap between guidelines and reality: type 2 diabetes in a National Diabetes Register 1996-2003. Diabet Med 2005; 22: 1420-1426.

6 Davies M. The reality of glycaemic control in insulin treated diabetes: defining the clinical challenges. Int J Obes Relat Metab Disord 2004; 28 (Suppl. 2): S14-S22.

7 LaMonte MJ, Blair SN, Church TS. Physical activity and diabetes prevention. J Appl Physiol 2005; 99: 1205-1213.

8 Liberopoulos EN, Tsouli S, Mikhailidis DP, Elisaf MS. Preventing type 2 diabetes in high risk patients: an overview of lifestyle and pharmacological measures. Curr Drug Targets 2006; 7: 211-228.

9 Koenigsberg MR, Bartlett D, Cramer JS. Facilitating treatment adherence with lifestyle changes in diabetes. Am Fam Physician 2004; 69: 309-316.

10 Steppel JH, Horton ES. Beta-cell failure in the pathogenesis of type 2 diabetes mellitus. Curr Diab Rep 2004; 4: 169-175.

11 Leahy JL. Pathogenesis of type 2 diabetes mellitus. Arch Med Res 2005; 36: 197-209.

12 Monnier L, Colette C, Rabasa-Lhoret R et al. Morning hyperglycemic excursions: a constant failure in the metabolic control of non-insulin-using patients with type 2 diabetes. Diabetes Care 2002; 25: 737-741.

13 Turner R, Cull C, Frighi V, Holmann R. Glycemic control with diet, sulfonylurea, metformin, or insulin in patients with type 2 diabetes mellitus: progressive requirement for multiple therapies (UKPDS 49). UK Prospective Diabetes Study (UKPDS) Group. JAMA 1999; 281: 2005-2012.

14 Bell DS, Ovalle F. Long-term efficacy of triple oral therapy for type 2 diabetes mellitus. Endocr Pract 2002; 8: 271-275.

15 Korytkowski M. When oral agents fail: practical barriers to starting insulin. Int J Obes Relat Metab Disord 2002; 26: S18-S24.

16 Peyrot M, Rubin RR, Lauritzen T et al. Resistance to insulin therapy among patients and providers: results 
of the cross-national Diabetes Attitudes, Wishes, and Needs (DAWN) study. Diabetes Care 2005; 28: 26732679.

17 Lepore M, Pampanelli S, Fanelli C et al. Pharmacokinetics and pharmacodynamics of subcutaneous injection of long-acting human insulin analog glargine, NPH insulin, and ultralente human insulin and continuous subcutaneous infusion of insulin lispro. Diabetes 2000; 49: $2142-2148$.

18 HOE 901/2004 Study Investigators Group. Safety and efficacy of insulin glargine (HOE 901) versus NPH insulin in combination with oral treatment in type 2 diabetic patients. Diabet Med 2003; 20: 545-551.

19 Massi-Benedetti M, Herz M, Pfeiffer C. The effects of acute exercise on metabolic control in type 2 diabetic patients treated with glimepiride or glibenclamide. Horm Metab Res 1996; 28: 451-455.

20 Yki-Järvinen H, Dressler A, Ziemen M. Less nocturnal hypoglycemia and better post-dinner glucose control with bedtime insulin glargine compared with bedtime $\mathrm{NPH}$ insulin during insulin combination therapy in type 2 diabetes. HOE 901/3002 Study Group. Diabetes Care 2000; 23: 1130-1136.

21 Yki-Jarvinen H, Kauppinen-Makelin R, Tiikkainen M et al. Insulin glargine or NPH combined with metformin in type 2 diabetes: the LANMET study. Diabetologia 2006; 49: 442-451.

22 Fritsche A, Schweitzer M, Haring H-U; 4001 Study Group. Glimepiride combined with morning insulin glargine, bedtime neutral protamine hagedorn insulin, or bedtime insulin glargine in patients with type 2 diabetes. A randomized, controlled trial. Ann Intern Med 2003; 138: 952-959.

23 Fonseca V, Bell DS, Berger S, Thomson S, Mecca TE. A comparison of bedtime insulin glargine with bedtime neutral protamine hagedorn insulin in patients with type 2 diabetes: subgroup analysis of patients taking once-daily insulin in a multicenter, randomized, parallel group study. Am J Med Sci 2004; 328: 274-280.

24 Rosenstock J, Schwartz SL, Clark CM Jr, Park GD, Donley DW, Edwards MB. Basal insulin therapy in type 2 diabetes: 28-week comparison of insulin glargine (HOE 901) and NPH insulin. Diabetes Care 2001; 24: 631-636.

25 Riddle M, Rosenstock J, Gerich J; Insulin Glargine 4002 Study Investigators. The Treat-to-Target Trial: randomized addition of glargine or human NPH insulin to oral therapy of type 2 diabetic patients. Diabetes Care 2003; 26: $3080-3086$.

26 Lechleitner M, Roden M, Haehling E, Mueller M. Insulin glargine in combination with oral antidiabetic drugs as a cost-equivalent alternative to conventional insulin therapy in type 2 diabetes mellitus. Wien Klin Wochenschr 2005; 117: 593-598.

27 Rosenstock J, Sugimoto D, Strange P, Stewart JA, Soltes-Rak E, Dailey G. Triple therapy in type 2 diabetes: insulin glargine or rosiglitazone added to combination therapy of sulfonylurea plus metformin in insulinnaive patients. Diabetes Care 2006; 29: 554-559.

28 Davies M, Storms F, Shutler S, Bianchi-Biscay M, Gomis R. Improvement of glycemic control in subjects with poorly controlled type 2 diabetes: comparison of two treatment algorithms using insulin glargine. Diabetes Care 2005; 28: 1282-1288.

29 Marshall SM, Barth JH. Standardization of HbA1c measurements - a consensus statement. Diabet Med 2000; 17: 5-6.

30 Marshall SM, Home PD, Manley SE, Barth JH, John WG. Standardization of glycated haemoglobin. Diabet Med 2002; 19: 429.

31 Fulcher GR, Storms F, Shutler S, Leperlier C, Gomis R, Davies M. Initiation of insulin glargine in patients with type 2 diabetes sub-optimally controlled on once-or twicedaily NPH insulin: results from the AT.LANTUS Trial. European Association for the Study of Diabetes Annual Congress. Diabetologia (Munich) 2004; 47(Suppl. 1): 272(Abstract 750).

32 Davies M, Storms F, Shutler S, Bianchi-Biscay M, Gomis R. Initiation of insulin glargine in type 2 patients with suboptimal glycaemic control on twice-daily premix insulin: results from the AT.LANTUS Trial. European Association for the Study of Diabetes. Diabetologia (Munich)2004; 47 (Suppl. 1): 56(Abstract 146).

33 Cryer PE. Hypoglycaemia: the limiting factor in the glycaemic management of type I and type II diabetes. Diabetologia 2002; 45: 937-948.

34 United Kingdom Prospective Diabetes Study Group. Intensive blood-glucose control with sulphonylureas or insulin compared with conventional treatment and risk of complications in patients with type 2 diabetes (UKPDS 33). Lancet 1998; 352: 837-853.

35 Raskin P, Allen E, Hollander P et al. Initiating insulin therapy in type 2 diabetes: a comparison of biphasic and basal insulin analogs. Diabetes Care 2005; 28: 260-265.

36 Charbonnel B, Dormandy J, Erdmann E, Massi-Benedetti M, Skene A. The prospective pioglitazone clinical trial in macrovascular events (PROactive): can pioglitazone reduce cardiovascular events in diabetes? Study design and baseline characteristics of 5238 patients. Diabetes Care 2004; 27: 1647-1653.

37 Nathan DM, Buse JB, Davidson MB et al. Management of hyperglycemia in type 2 diabetes: a consensus algorithm for the initiation and adjustment of therapy: a consensus statement from the American Diabetes Association and the European Association for the Study of Diabetes. Diabetes Care 2006; 29: 1963-1972.

38 Rosenstock J, Dailey G, Massi-Benedetti M, Fritsche A, Lin Z, Salzman A. Reduced hypoglycemia risk with insulin glargine: a meta-analysis comparing insulin glargine with human NPH insulin in type 2 diabetes. Diabetes Care 2005; 28: 950-955. 
39 Massi Benedetti M, Humburg E, Dressler A, Ziemen M. A one-year, randomised, multicentre trial comparing insulin glargine with NPH insulin in combination with oral agents in patients with type 2 diabetes. Horm Metab Res 2003; 35: 189-196.

40 Janka HU, Plewe G, Riddle MC, Kliebe-Frisch C, Schweitzer MA, Yki-Jarvinen H. Comparison of basal insulin added to oral agents versus twice-daily premixed insulin as initial insulin therapy for type 2 diabetes. Diabetes Care 2005; 28: 254-259.

41 Malone JK, Kerr LF, Campaigne BN, Sachson RA, Holcombe JH. Combined therapy with insulin lispro Mix 75/25 plus metformin or insulin glargine plus metformin: a 16-week, randomized, open-label, crossover study in patients with type 2 diabetes beginning insulin therapy. Clin Ther 2004; 26: 2034-2044.

42 Snoek FJ, Dain M-P, Polonsky WH. Perceptions of seriousness and management of diabetes. Findings from the SHARED study (Survey comparing Healthcare professionals and patients to Assess REal perceptions of Diabetes issues). Diabetologia 2006; 49: 551 (Abstract 0905).

43 Yki-Jarvinen H, Juurinen L, Alvarsson $\mathrm{M}$ et al. Initiate insulin by aggressive titration and education (INITIATE): a randomized study to compare initiation of insulin combination therapy in type 2 diabetic patients individually and in groups. Diabetes Care 2007; 30: 1364-1369.

\section{Appendix}

\section{List of Investigators by Country}

Algeria: Nassima Ait Chaffa, Arbouche, Aribi, Ayad, Bachaoui, Mohamed Belhadj, Fafa Bouabdallah, Aissa Boudiba, Bouyoucef, Hafida Cherif, Rabea Chouaki, Slimane Khalfa, Safia Mimouni-Zerguini, Fouzia Sekkal, Tassat and Sihem Tegguiche. Argentia: Maria Cristina Bazan, Elias Bulesevich, Alberto Burruchaga, Monica Campero, Lucio Cicchitti, Victor Commendatore, Juan Corvalan, Jose Costa Gil, Monica Damiano, Luis De Loredo, Marcelo Franchino, Gustavo Gazze, Maria Cristina Grossman, Sonia Hermida, Elias Hofman, Silvia Lapertosa, Ruben Lutfi, Alejandro Misiunas, Roque Niklison, Alberto Rodriguez Triffiletti, Estela Rovira, Marcelo Slimel, Pedro Tesone and Omar Yacante. Australia: Kerry Bowen, John Carter, Roger Chen, Wah Cheung, Michael D. Emden, Timothy Davis, Peter Davoren, T. Diamond, Jeff Flack, Greg Fulcher, R. Gilbert, David Irvine, Beggs Jenny, George Jerums, Warren Kidson, Andrew Lang, Andrew Lowy, Jaye Martin, Alison Nankervis, Nikolai Petrovsky, Pat Phillips, John Prins, Anthony Roberts, Richard Simpson, Ray Slobodniuk, Kim Stanton and Yong Mong Tan. Austria: Elisabeth Braendle, Michael
Guschlbauer, Sybille Guschlbauer-Heilig, Martin Haid, Anton Hartweger, Richard Klinger, Martin Lischnig, Anita Luiskandl, Rudolf Prager, Susanne Pusarnig, Franz Rainer, Erich Schaflinger, Sonja Schwarz, Carola Stehli, Franz Stradner, Mario Untersalmberger and Tatjana Wiesinger. Belgium: Paul Arnouts, Annemieke Beirinckx, Andre Bodson, Marie-Sylvie Bouquegneau, Vincent Col, Jean-Luc Coolens, Francis Coucke, Luc Derdelinckx, Etienne Duvivier, Isabelle Geronooz, Christiane Herbaut, Gerard Hubermont, Bart Keymeulen, Yves Kockaerts, Georges Krzentowski, Gerard Lamberights, Andre Leblanc, Claire Litvine, Dr Malherbe, Christian Malherbe, Frank Nobels, Isabelle Paris, Christina Pelckmans, Hubert Penninckx, Claire Rémy, Denis Scarniere, Cecile Soyez, Paul Taelman, Jozef Tits, Kristien Van Acker, Eric Van Aken, Sylva Van Imschoot, Dirk Van Nimmen, Etienne Vanfleteren and Roger Wirion. Brazil: Antonio Chacra, Thomas Cruz, Lucas José De Campos Machado, Jose Egidio De Oliveira, Marco Antonio Dias, Freddy Eliaschewitz, Vivian Ellinger, Reine Fonseca, Adriana Forti, Fadlo Fraige Filho, Laercio Franco, Marilia Gomes, Miguel Hissa, Wilson Jacob Filho, Antonio Carlos Lerario, Geisa Maria Macedo, Osmar Monte, Edgar Niclewicz, Edgar Niclewicz, Hermelinda Pedrosa, Nelson Rassi, Giuseppe Repetto, Jose Augusto Sgarbi, Marcos Antonio Tambascia, Balduino Tschiedel, Rosa Vargas, Leao Zagury, Leao Zagury and Maria Tereza Zanella. Bulgaria: Vladimir Christov, Ivona Daskalova, Petia Karatodorova, Dragomir Koev, Lidiya Koeva, Angel Marinchev, Milena Petrova and Nataliya Temelkova. Cameroon: Felix Assah and Jean-Claude Mbanya. Columbia: Santamaria Adriana, Valenzuela Alex, Joaquin Armenta, Argemiro Fragozo, Ana Gomez, William Kattah, Adriana Lema, Dilcia Lujan, Arbelaez Patricia, Laura Reyes, Laura Reyes and Maria Uruena. Costa Rica: Baudilio Mora and Luis C. Ramirez. Croatia: Izet Aganovic. Czech Republic: Jana Belobradkova, Jan Broz, Lenka Dohnalova, Daniela Kallmunzerova, Alena Klimovicova, Zdenka Krejsova, Karel Kren, Milan Kvapil, Terezie Pelikanova, Jindriska Perusicova, Zdenek Rusavy, Olga Skarpova, Alena Smahelova, Viera Zackova and Emil Zahumensky. Ecuador: Marina Moreno, Miguel Pasquel, Angel Salazar and Marino Tagle. Egypt: Ali Abbassy, Khalifa Abdallah, Maged Abdel Aal, Mohamed Abdel Aziz, Sameh Abdel Shakour, Megahid Abou El Maged, Fahmy Amara, Samir Asaad, Mohamed El Bahrawi, Hisham El Gyar, Ibrahim El Ibrashy, Nabil El Kafrawi, Hussein Eloraby, Isis Ghali, Yehia Ghanem, Sherif Hafez, Ragey Henry, Salah Ibrahim, Mohamed Kamer, Moughazy Mahgoub, Samir Naem, Raefat Rashwan, Ragheb Refaey, Hassan Rizk, Mona Salem, Hosni Shahin, Salah Shelbaya, Mohamed Sheta, Mabaheg Souka and Assem Zeyada. Estonia: Anu Ambos, 
Aili Janson, Jaanus Kerge, Ebe Rooks, Pille Rudenko, Hiie Tupits and Liina Viitas. French Polynesia: Jean Louis Boissin, Sandrine Laboureau-Soares, Frederique Rachedi. French West Indies: Sonia Benabdallah, JeanPaul Donnet, Pauline Kangambega, Yolaine Longchamps, Catherine Messerschmitt, Socrate Phirai, Miguelle Rosette-Narece, Gerard Sorel and Michele Vado-Prudent. Greece: Eleni Anastasiou, Christos Bartsocas, Marian Benroubi, Elefteria Giannoulaki, Ioannis Ioannidis, Dimitrios Karamitsos, Nikolaos Katsilambros, Andreas Melidonis, Ilias Migdalis, Emmanouil Pagkalos, Stavros Pappas, Costas Phenekos, Sotirios Raptis, George Skaragas, Nicolas Thalassinos, Dimitris Tsakataras, Agathocles Tsatsoulis and Christos Zoupas. Guatemala: Ronaldo Gonzalez, Luis A. Ramirez, Maya V. Serrano and Juan Siekavizza. Hong Kong: Karen Lam, Ip Tim Lau, Ka Fai Lee, Jenny Leung, Kwok Wing Lo, Shing Chung Siu and Man Wo Tsang. Hungary: Erzsebet Domotor, Jozsef Fovenyi, Mihaly Gurzo, Andras Gyimesi, Miklos Kaplar, Laszlo Kautzky, Gyula Neuwirth, Tamas Oroszlan, Pal Panczel, Csaba Ruzsa, Aniko Somogyi, Hidvegi Tibor, Laszlo Ujszaszy, Gyozo Vandorfi and Tamas Varkonyi. India: Moses Anand, Mala Dharmalingam, Shashank Joshi, H. Nagamani, Jayasimha Reddy, Bipin Sethi, S. Subhasree and Sundaram Sundaram. Indonesia: Sidartawan Soegondo and Askandar Tjokroprawiro. Ireland: John Barton, Brendan Buckley, Brendan Kinsley, Fionnuala Lavin, Joseph Mckenna, Brendan Mcmahon, Patrick Murphy, John Nolan, Tim Obrien, Seamus Sreenan and Peter Weineke. Israel: Zaina Adnan, Hanoch BarOn, Maya Berla, Simona Braginski, Andreas Buchs, Ohad Cohen, Yosi Cohen, Deeb Daoud, Ilana Harman, Avraham Tommy Herskovits, Yaroslav Itskovich, Yoram Kanter, Avraham Karasik, Eddy Karnieli, Kish, Hila Knobler, Michael Koffler, Dinorah Krysztal Jonio, Agnesa Lucomsky, Alexander Lustig, Revital Nimri, Feige Nirevich, Clara Noemi Norymberg Alfici, Hussein Osamah, Moshe Phillip, Rita Rachmany, Micha Rapoport, Mordchai Ravid, Itamar Raz, Marina Remesnik, Yael Shahor, Naim Shehadeh, Tatiana Shuster, Joelle Attal Singer, Ervin Stern, Gloria Tsvetov, Julio Wainstein, Yair Yerushalmi and Tayba Zornitski. Ivory Coast: Lokrou Adrien. Korea: Chulwoo Ahn, Junhyeop An, Inkyoung Choi, Mijung Eun, Moonsook Jo, Sun-Woo Kim, Eungjin Kim, Hye Soon Kim, Yong-Ki Kim, Inju Kim, Kyung-Rae Kim, Dolmi Kim, Duk-Hee Kim, Kyungsoo Ko, Oknyu Kong, Wonyoung Lee, In-Kyu Lee, Hyoung-Woo Lee, Sihyung Lee, Kyung-Wan Min, HongSun Paik, Taesun Park, Jihyun Park, Byoungdoo Rhee, Choongho Shin, Seokman Son, Kyuchang Won, Sei-Won Yang and Soojee Yoon. Kuwait: Nabila Abdella, Monira Al-Arouj, Abdullah Ben Nakhi, Soliman El Gebely and
Hisham El Mohanedy. Latvia: Baiba Ansmite, Aivars Galvins, Ilze Konrade, Inta Leitane, Aivars Lejnieks, Mara Marga, Valdis Pirags, Ingvars Rasa, Rota Ritenberga, Sandra Steina and Ieva Strele. Lebanon: Mario Aoun, Antoine Arkieh, Chawki Atallah, Paola Atallah, Sami Azar, Alexandre Cheaib, Georges Halaby, Kamal Hirbli, Selim Jambart, Elie Karameh, Rita Medlej, Pierre Najm, Charles Saab, Munzer Saleh, Ibrahim Salti and Richard Yazbeck. Lithuania: Sigita Gailiuniene, Saulius Grigonis, Nijole Jurgeviciene, Rima Jurgutyte, Rasa Juskiene, Jurate Lasiene, Antanas Navickas, Antanas Norkus, Jurgis Algirdas Pliuskys, Rita Sulcaite, Marijona Sulskiene, Bronislava Urbonaite and Rasa Ziukaite. Malaysia: Siew Pheng Chan, Soon Heng Chew, Rokiah Pendek, Ikram Shah and Shireene Ratna Vethakkan. Mexico: Sara Arellano, Margarita Barrientos, Cesar Calvo, Rutila Castaneda, Maria Comellas, Leonides Cortinas, Natalia Delagarza, Carlos Dominguez, Miguel Escalante, Antonio Escalante, Salvador Escorcia, Hector Garcia, Christelle Genestier, Francisco Gomez, David Gonzalez, Alicia Ibarra, Jaime Illescas, Marisela Jimenez, Fernando Lavalle-Gonzalez, Luis Mejia, Carlos Mendoza, Ignacio Mendoza, Tereza Munoz, Victoria Padilla, Ignacio Pineda, Carmen Ramos, Hector Tamez, Lubia Velazquez, Maricela Vidrio, Margarita Zamora and Sergio Zuñiga. Morocco: Kadiri Abdelkrim, Sanaa Al Abadane, Badr-Eddine Aquedim, Pr Jamal Belkhadir, Jamal-Dine Bensouda, Joelle Cariou Belqadi, Khadija Cherkaoui, Abdelmjid Chraibi, Hassan El Ghomari, Fatima Marouan, Abdelhaq Mikou, Malika Naciri, Amina Nadir and Zineb Slaoui. the Netherlands: M. G. A. Baggen, J. A. M. Beentjes, R. Bianchi, A. Binnerts, Eddy Blaauwwiekel, Bob Borger Van Der Burg, J. G. S. Breed, Catherine Brouwer, Paul Cromme, Eelco De Koning, A. Dolman, E. Simons, Jan Willem Elte, Jack Heijster, Klaas Hoogenberg, Roel P. L. M. Hoogma, Frank Huvers, Paul H. Th. Koch, Paul Leurs, Anko Lie, Th. L. J. M. Loos Van Der, W. Numan, Bert Jan Potter Van Loon, Stephen Riemens, Peter Rosekrans, August Schlosser, Cor Schop, J. M. Sepers, G. E. M. G. Storms, John Van Bork, Jan Van Der Werf, A. Veerman, Peter Viergever, Jeroen Vincent, P. Wessels, A. Wester, A. M. H. Wetzels and Erik Wins. New Caledonia: Pierre-Marie Bescond and Isabelle Descamps. Pakistan: M. A Ebrahim, Zahid Yaseen Hashmie, Shahid Mahmood, Najib Ul-Haq and Jamal Zafar. Paraguay: Gilda Benitez, Jorge Tadeo Jimenez and Mafalda Palacios. Peru: Hugo Arbañil, Maritza Goya, Miluska Huachin, Rosa Pando and Jaime Villena. Philippines: Joselynna Anel-Quimpo, Cynthia Chua-Ho, Thelma Crisostomo, Richard Elwyn Fernando, Ruby Go, Honolina Gomez, Frances Lina Lantion-Ang, Frances Lina Lantion-Ang, Mary Anne 
Lim-Abrahan, Mary Anne Lim-Abrahan, Araceli Panelo, Elizabeth Paz-Pacheco, May Sison and Rosa Allyn Sy. Poland: Malgorzata Bernas, Anna Czech, Leszek Czupryniak, Wladyslaw Grzeszczak, Janusz Gumprecht, Danuta Jakubczyk, Krystyna Jedynasty, Waldemar Karnafel, Teresa Kasperska-Czyżyk, Ida Kinalska, Marek Kowrach, Elzbieta Kozek, Janusz Krzymien, Elzbieta Kunikowska-Orlowska, Roman Laz, Jerzy Loba, Monika Lukaszewicz, Anna Majchrzak, Lilianna Majkowska, Krystyna Matuszewska, Piotr Moleda, Dorota PisarczykWiza, Grzegorz Rosinski, Jan Ruxer, Malgorzata Saryusz-Wolska, Ewa Semetkowska-Jurkiewicz, Jacek Sieradzki, Adam Stefanski, Zofia Szczeklik-Kumala, Malgorzata Szelachowska, Jolanta Topolska, Jacek Walewski, Krzysztof Wanic, Bogna Wierusz-Wysocka, Bogumil Wolnik and Marcin Zychma. Portugal: Claudia Amaral, Manuel Boavida, Sérgio Borges, José Bragança Parreira, Jorge Caldeira, Manuela Carvaleiro, Rui Cesar, Alvaro Coelho, Ricardo Conceição, Luisa Cortesao, Luísa Cortez, Davide De Carvalho, Rui Duarte, Joao Duarte, Ana Figueiredo, Paula Freitas, Luís Gardete, Cástor Gil, Laura Guerra, Olinda Marques, Teresa Martins, Luis Medina, Maria Isabel Meneses, Celestino Neves, Joao Nunes Correa, Simoes Pereira, Cristina Ribeiro, Arnaldo Sá, Luisa Sagreira, Sílvia Saraiva, Amílcar Silva, Francisco Silvestre Abreu, Ana Varela, Carlos Vasconcelos, Joana Vilaverde and Cristina Xavier. Romania: Cornella Bala, Gina Botnariu, Anca Cerghizan, Livia Duma, Mariana Graur, Cristian Guja, Nicole Hancu, Constantine Ionescu, Maria Mota, Camelia Panus, Gabriela Roman, Mihaela Rosu, Octavian Savu, Viorel Serban, Alexandra Sima, Ioan Verslu, Adrian Viad and Mihaela Voltec. Russia: Zalevskaya Alsy, Alexandr Ametov, Mikhail Balabolkin, Galina Melnichenko, Maria Pavlova, Marina Shestakova and Natalia Vorokhobina. Saudi Arabia: Abdulaziz Al Twaim, Ameera Al-Dossary, Abdulmohsen Al-Elq, Khalid Al-Rubeaan and Shasqt Bashir. Senegal: Said Norou Diop. Singapore: Florence Tan and Ah Chuan Thai. Slovakia: Silvia Dokusora, Helena Imreova, Boris Krahulec, Emil Martinka, Lujza Strbova and Vladimir Uliciansky. Slovenia: Tadej Battelino, Nusa Cede, Miro Cokolic, Mihael Koselj, Lucka Kostansek, Marko Medvescek, Franc Mrevlje, Maja Ravnikoblak, Jurij Subic, Marjeta Tomazic, Vilma Urbancic, Natasa Ursic Bratina, Gregor Veninsek, Matjaz Vrtovec, Matej ZavråjNik and Andrej Zavratnik. South Africa: F. Bonnici, E. L. Brauns, Larry Distiller, Utham Govind, F. Haffejee, B. Joffe, J. Kalk, Betsie Kloppers, E. Kok, B. Kramer, Deepak Lakha, C. Mendes, Louis Minders, P. A. Moodley, Ray Moore, Sean Murray, Mohamed Omar, Areti Philotheou, E. Polakow, A. Postma and Neville Welling- ton. Spain: Miguel Albero, Isabel Alonso, Cesar Alonso, Carlos Alsina, Leticia Arman Alvarez-Buylla, Ricardo Astorga, Antonio Becerra Fernandez, Juan Jose Beitia Martin, Diego Bellido, Pedro Benito, Benito Blanco, Evangelina Boix Carreño, Marta Botella, Carlos Brotons, Jose Bueno, Jose Cabezas, Alberto Calderon, Alfonso Calle, Juan Francisco Cano, Maria Jose Carrera, Felipe Casanueva, Lluis Comino Sillero, Luis A. Cuellar, Luis De Teresa, Javier Diez, Jose Ramon Dominguez Escribano, Santiago Duran, Ramon Elorza, Fernando Escobar, Xavier Farrãs, Eduardo Faure, Africa Garcia, Jorge Garcia, Andres Garcia Centenera, Francisco J. Garcia Soidan, Olga Gimenez Palop, Ramon Gomis, Stella Gonzalez, Angeles Gonzalo, Jose Luis Griera, Eduardo Guerrero, Federico Hawkins, Josep Maria Hernandez, Antonio Hernandez Mijares, Jose Luis Herrera Pombo, Natalia Hillman, Albert Ledesma, Jose Andres Maldonado, Pilar Manzano, Juan Pedro Marañes Pallardo, Angel Luis Marco Mur, Victor Martin, Didac Mauricio Puente, Luis Miguel Miranda, Maria J. Morales, Susana Moreno, Xavier Mundet, Javier Novoa, Albert Palaudaries, Felipe Pallardo, Francisca Payeras Mas, Joaquin Pelleja, Antonio Pico Alfoso, Francisco Piñon Selles, Francisco Jose Pomares Gomez, Jaume Puig, Antuna De Alaiz Ramiro, M. Jose Roche Asensio, Enrique Ruiz, Pilar Saavedra, Jose Saban, Javier Salvador, Javier Sangros, Manuel Serrano Rios, Marta Serrarols, Juan Soler Ramon, Manel Terns, Luis Fernando Vences Benito and Ovidio Vidal. Switzerland: Frank Achermann, Martin Baebler, Barbara Felix, Jean-Jacques Grimm, Ulrich Keller, Francois Kuntschen, Elisabeth Nuetzi, Bettina Peter, Jacques Philippe, Andreas Rohrer, Karl Scheidegger and Claude Schoenenweid. Taiwan: Chwen-Tzuei Chang, Szu-Tah Chen, Bai-Hsiun Chen, Chi-Yuan Cheng, Jeng-Bin Chiou, Chien-Wen Chou, Lee-Ming Chuang, ShinnTzong Gong, Low-Tone Ho, Chang-Hsun Hsieh, Chung -Yen Huang, Shi-Wen Kuo, Ching-Fai Kwok, Shih-Ming Lai, Ching-Hsiang Leung, Jen-Der Lin, Ching-Ling Lin, Kwo-Chuan Lin, Yung Chuan Lu, Horng-Yih Ou, Dee Pei, Kuang-Chung Shih, San-Ging Shu, Jui-Hung Sun, Dong-Hwa Tsai, Shih-Te Tu, Chao-Hung Wang, PeiWen Wang, Hsiao-Fen Weng, Huey-Peir Wu, Ta-Jen $\mathrm{Wu}$ and Chwen-Yi Yang. Thailand: Sunitaya Chandraprasert, Chaicharn Deerochanawong, Nopawan Kittivat, Natapong Kosachunhanun, Ampica Mangklabruks, Saroj Nimkarn, Wannee Nitiyanant, Nawaporn Numbenjapon, Pairunyar Sawathiparnich and Sutin Sriussadaporn. Trinidad and Tobago: Surujpaul Teelucksingh. Tunisia: Mohamed Abid, Nejib Ben Abdallah, Fathi Ben Khalifa, Silvia Mahjoub, Lilia Rokbani and Hedia Slimen. Turkey: Metin Arslan, Goksun Ayvaz, Neslihan Bascil Tutuncu, Nilgun Baskal, Mehtap Colak, 
Abdurrahman Comlekci, Taner Damci, Gurbuz Erdogan, Murat Erdogan, Faruk Ergonen, Canan Ersoy, Hasan Ilkova, Sazi Imamoglu, Ayhan Karakoc, Osman Koseoglulari, Balci Mustafa Kemal, Zeynep Osar, Mine Ozduman Cin, Ramazan Sari, Ozay Tiryakioglu, Ercan Tuncel, Mehmet Tuzun, Gokhan Yazicioglu, Sena Yesil, İhan Yetkin, Murat Yilmaz and Candeger Yilmaz. Ukraine: Maryna Baluk, Victor Belinsky, Petro Bodnar, Yuriy Brechko, Victoriya Chernikova, Maryna Chukmasova, Anatoly Degonsky, Yuriy Karachentsev, Liliya Knishevitskaya, Vadim Korpachev, Alla Kovalchuk, Nonna Kravtchun, Nataliya Kushnarova, Eugeny Martsinik, Galina Mikhaltchishin, Tatiyna Pertseva, Alla Peshko, Segey Tkach, Mikola Tronko and Margarita Ziablitseva. United Arab Emirates: Omniyat Al-Hajeri, Mahmoud Benbarka, Ghaida Kaddaha and Ali Khalil. UK: Dr Abbott, Khalid Ahmed, Thomas Akintewe, Moyra Anderson, W. J. Andrews, Tim Anglin, Stephen Atkin, Arun Baksi, Howard Ball, Maria Barnard, Anthony Barnett, Richard Barnsley, Stephen Beer, Mark Blagden, Trevor Blair, Roger Blandford, Shirine Boardman, Dr C. Bodmer, Les Borthwick, Dr Borthwick, Paul Bowron, Tina Burdett, John Burke, Albert Burton, James Butler, Dr M Butler, Ian Caldwell, Gordon Caldwell, John Cecil, Patrick Chong, Dr John Clark, Andrew Collier, John Cran, Adrian Darrah, Sean Dinneen, Mike Duckworth, Sion Edwards, Richard Edwards, Adam Ellery, Richard Evans, Barrie Fisher, Norman John Fletcher, Paul Fletcher, Charles Fox, Richard Frankel, Ian Gallen, Wendy Gatling, Dr Emad George, Martin
Gibson, Stephen Gilbey, A. Gossage, Rob Gregory, Kathryn M. Hall, Dr Hall, James Hampton, Helen Hards, Simon Heller, David Hepburn, Kitty Holmes, David Hopkins, Sharaf Ibrahim, Alan Jaap, Neil Jackson, David Jarvis, Manjit Jaspal, Sujeet Jha, Andrew Johnson, John Jones, Nick Jones, Dr G Jones, Frank Joseph, Stonny Joseph, Edward Jude, Emran Kahn, David Kerr, Colin Kesson, Stephen Kidman, Krishna Korlipara, Abdul Lakhdar, David Large, Ted Leverton, Jennifer Litchfield, Jean Macleod, Dr G. Mcansh, Douglas Mckeith, John Mcknight, Serife Mehmet, Cummings Michael, Diane Morgan, Andrew Morris, Iqbal Nagpal, Robert Nam, Khash Nikookam, Maurice O. Kane, Paul Ohare, Brenden Omalley, Ian Orpen, David Owens, Mike Page, Arashia Panahloo, Graham Parker, Stephen Parr Burman, Jonathan Pinkney, Tony Piper, David Price, Gerrard Rayman, Douglas A. Robertson, Tony Robinson, Dr Jonathan Roland, Steve Rowlands, John Ryan, M Sampson, Andrew Sanderson, John Scarpello, Ian Scobie, Dr Scott, Barry Silvert, Jeremy Simmons, H. Simpson, Robert Simpson, P. Singhal, M. Small, Christopher Speirs, Keith Steer, Christopher Strang, Jonathon Thow, John Tilley, Hilary Tindall, Nick Vaughan, Mark Vella, Jolanta Weaver, John Wheal, Trevor Wheatley, Helen White, Philip Wiles, Meurig Williams, Michael Wright, Nell Wyatt and Alexander Young. Uruguay: Cristina Belzarena, Rosario Bueno, Ana Maria Jorge and Maria Del Pilar Serra. Venezuela: Luis Chacin, Samuel Chocron, Mariela Paoli and Humberto Valbuena. Yugoslavia: Nebojsa Lalic, Katarina Lalic and Dragan Micic. 